\title{
Effect of Temperature and Duration of Maceration on Colour and Sensory Properties of Red Wine - A Review
}

\author{
H. Şener \\ Biotechnology Branch, Institute of Natural and Applied Sciences, Ege University, Turkey \\ Submitted for publication: December 2017 \\ Accepted for publication: March 2018
}

Key words: Cold maceration, skin contact, total phenols, aroma, colour, wine

\begin{abstract}
The maceration process plays an important role in the composition of the colour and sensory properties of red wine by facilitating the extraction of phenolic and aromatic compounds found in grapes. This review summarises the key findings from a study of the literature associated with research on the effects of the temperature and duration of maceration on the phenolic content, colour and sensory properties of red wine. In the past, many researchers have reported that higher maceration temperatures increase the extraction of phenolic compounds and enhance red wine colour, but low-temperature pre-fermentative techniques have become more popular in recent years due to their positive effects on wine composition, including lower oxidation of anthocyanin pigments and aroma compounds, inhibition of undesirable enzymatic activities, and an environment that is less conductive to microbial growth. Macerations carried out at low temperature ranges $\left(10^{\circ} \mathrm{C}\right.$ to $\left.15^{\circ} \mathrm{C}\right)$ result in red wines with the highest levels of total phenolic content, anthocyanin and colour intensity, and richer fruity, flowery and spicy aroma. The duration of maceration has also been shown to have significant effects on red wine phenolic compounds, colour properties and the relevant sensory attributes. Studies show that prolonged maceration leads to a stable red colour, as well as richer tannin content, polymeric pigments and astringency. Red wines with appropriate colour and sensory characteristics can be produced by adapting both maceration temperature and duration to the desired style.
\end{abstract}

\section{INTRODUCTION}

Wine is an alcoholic beverage made up of various chemical compounds, including aroma constituents, organic acids and phenolic compounds, and all these compounds play an important role in the quality of the wine. The majority of aroma and phenolic compounds are extracted during the fermentation and/or maceration process (Mazza \& Miniati, 1993; Gomez-Plaza et al., 2002; Monagas et al., 2005; Koyama et al., 2007). Distribution of these compounds within the grape berry is given in Fig. 1 .

Many factors can have an influence on the colour and aroma characteristics of the wine. These factors include grape variety, harvesting time, climatic conditions, soil characteristics, winemaking procedures and postproduction methods. They affect the quality characteristics of the wine individually and also through interaction with each other. The grape variety has an important main role in determining wine characteristics, but winemaking procedures also have a prominent effect on the wine quality. The vinification factors include yeast strains, fermentation time and temperature, ethanol content, mixing type, type and time of pressing, fining agents and filtration techniques. In recent years, a lot of effort has been devoted to the study of wine phenolics, and optimising oenological processes, in order to improve the wine sensory characteristics and obtain better quality products. Among all these factors, fermentation temperature and time have been shown to have significant impacts on the colour and sensory properties of the wine (Jackson \& Lombard, 1993; Auw et al., 1996; Gao et al., 1997; Girard et al., 1997; Glories, 1999; Girard et al., 2001; Cheynier et al., 2006).

The aim of this review is to summarise the importance of maceration time and temperature on the colour and sensory properties of red wine, and to emphasise particularly the importance of cold maceration temperatures. Therefore, studies that highlight these specific criteria were selected from the literature.
Aroma and colour compounds of red wine
The appearance and aroma of wine are widely recognised as important quality indicators. Wine aroma is composed of a large variety of volatile compounds with different aromatic characteristics. Terpenes, esters, aldehydes, volatile acids, higher alcohols and volatile phenolics are all included in the aromatic composition of wine. They originate from 


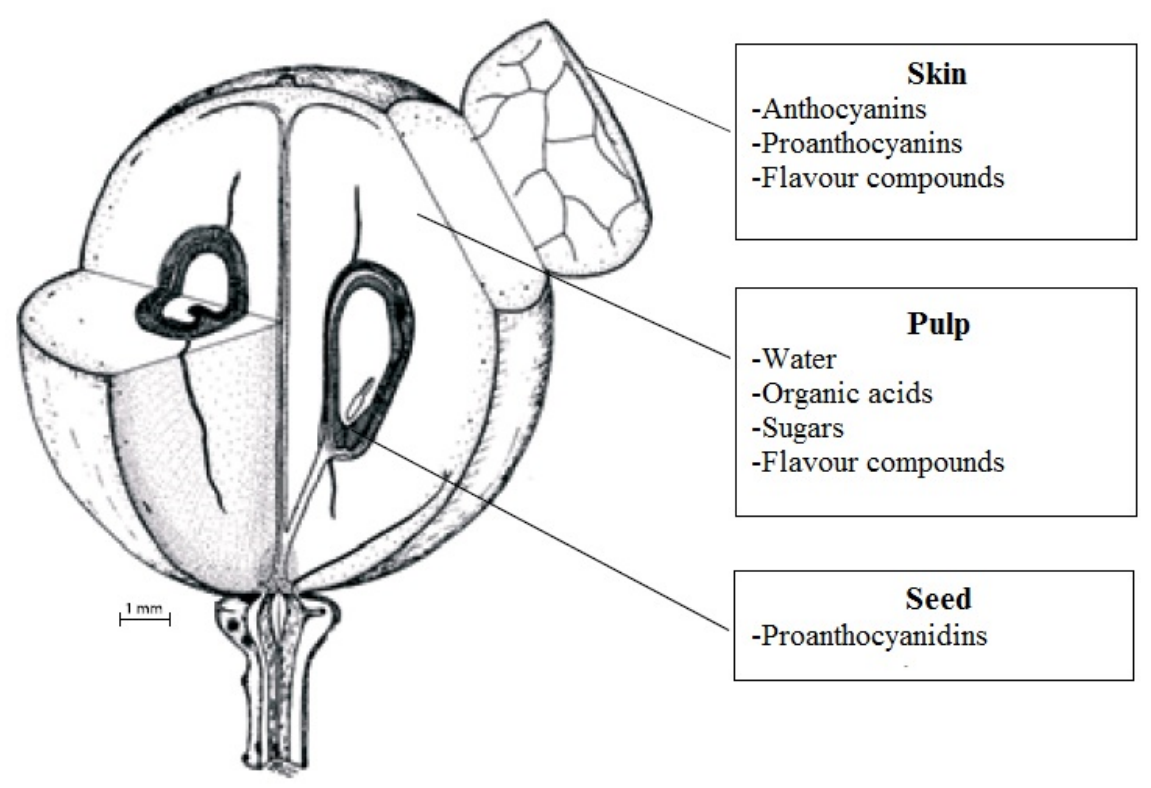

FIGURE 1

Distribution of compounds in a grape berry (Kennedy, 2008).

three main sources, namely the varietal (or primary) aroma, coming from the grape, the secondary aroma, produced during maceration and fermentation, and the tertiary aroma (sometimes called the bouquet), which results from the maturation and ageing process. One of the important groups of aroma compounds found in Vitis vinifera grapes are the terpenic compounds (Rapp, 1988; Palomo et al., 2005; Salinas et al., 2005, Pogorzelski \& Wilkowska, 2007), but there are many others that can be derived from the skins during maceration. According to several key studies, the duration and temperature of maceration have the largest impact on wine colour and aroma (Auw et al., 1996; Peinado et al., 2004; Monagas et al., 2005; Koyama et al., 2007).

The appearance of wine includes its colour, which gives not only the first and immediate impression but also it acts as a crucial quality indicator. Phenolic compounds found in wines are mainly responsible for colour and for the sensory attributes on the palate (Table 1). Anthocyanins (phenolic compounds extracted from grapes skins) play an important role in wine colour (Ribereau-Gayon \& Glories, 1987; Mazza, 1995; Glories, 1999; Salinas et al., 2005; Harbertson \& Spayd, 2006; Gil-Munoz et al., 2009). Other phenolic compounds, such as catechins, epicatechins and tannins, are associated with the bitterness and astringent properties of wines (Ribereau-Gayon \& Glories, 1987; Auw et al., 1996; Kallithraka et al., 1997; Vidal et al., 2003; Cheynier et al., 2006).

As the quantity and forms of anthocyanins are crucial to the quality of red wine, these will now be discussed in a little more detail. Anthocyanins can be glycosylated at the third position of the heterocycle of an anthocyanidin ( $V$. vinifera grapes), or have third and fifth positions ( $V$. rupertis, $V$. liparia and $V$. labrusca grapes). The basic structure of an acetylated anthocyanin found in red wines is given in Fig. 2, and compounds associated with different functional groups, all of which may be found in red wine, can be seen in Table 2 .

Anthocyanins may have different forms depending on various factors in their environment, such as $\mathrm{pH}$, temperature, metal ions, enzymes, oxygen, sulphur dioxide, etc. These different forms will affect reactivity, and various interactions and copigmentation reactions play an important role in the formation and stability of red wine colour. Flavonoids, polyphenols, amino acids, organic acids and anthocyanins can be associated with colour and become copigments in wine. These copigment complexes are important in colour stability in wine during maturation and ageing (Kanellis \& Roubelakis-Angelakis, 1993; Mazza \& Miniati, 1993; Boulton, 2001; Gutierrez et al., 2005). Other polyphenols, including catechins, epicatechins, epigallocatechins and tannins, are responsible for the bitterness and astringency of wine (Kennedy et al., 2006).

As colour plays such an important role in red wine quality, it is essential to be able to quantify changes and effects during winemaking. One of the most commonly accepted methods of determining the total phenolic content of red wine is a colorimetric assay of phenolic and polyphenolic antioxidants, the so-called 'Folin-Ciocalteu' method (also known as the gallic acid equivalence (GAE) method) (Singleton \& Rossi, 1965). In this method, diluted red wine samples are mixed with Folin-Ciocalteu reagent (a mixture of phosphomolybdate and phosphotungstate). The reagent will react with any reducing substance, and therefore measures the total reducing capacity of the wine, not just of the phenolic compounds. Absorbance of the solution is read at $765 \mathrm{~nm}$ with a UV/VIS spectrophotometer. Results are expressed as $\mathrm{mg} / \mathrm{L}$ gallic acid equivalents, and give a good indication of the total amount of phenolics extracted during maceration.

Absorbance measurements of red wine samples can be carried out using spectrophotometry at different 
wavelengths, which will provide information about different aspects of the wine's colour. The samples have to be clear and not contain carbon dioxide, which will interfere with the readings. Absorbance (A) values at 420, 520 and $620 \mathrm{~nm}$ are measured, and the following parameters are determined from these absorbance values (Glories, 1984): colour density $\left(\mathrm{CD}=\mathrm{A}_{420}+\mathrm{A}_{520}\right)$, colour intensity $\left(\mathrm{CI}=\mathrm{A}_{420}+\mathrm{A}_{520}+\mathrm{A}_{620}\right)$, tint value $\left(\mathrm{A}_{420} / \mathrm{A}_{520}\right)$, proportion of yellow colour $\left(\mathrm{A}_{420} / \mathrm{CI} \mathrm{x}\right.$ $100)$, proportion of red colour $\left(\mathrm{A}_{520} / \mathrm{CI} x \mathrm{100}\right)$ and proportion of blue colour $\left(\mathrm{A}_{620} / \mathrm{CI} \times \mathrm{100}\right)$.

Another analytical procedure useful in colour and phenolic measurement is the tristimulus analysis, which is also carried out on a spectrophotometer with the help of a match program. The so-called 'CIELAB' parameters can be determined by measuring the transmittance of wine every $10 \mathrm{~nm}$ over the visible spectrum (from 380 to $770 \mathrm{~nm}$ ), using the illuminant $\mathrm{D}_{65}$ and $10^{\circ} \mathrm{C}$ standard observer (Bakker et al., 1986; CIE, 1986). These parameters are: $L^{*}$, a measure of lightness; $a^{*}$, a measure of redness; $b^{*}$, a measure of yellowness; $C^{*}$, the chroma or saturation (square root of $a^{* 2}+b^{* 2}$ ); and $H^{*}$, the hue angle (Arctan of $b^{*} / a^{*}$ ). The results of all these analytical methods give oenologists useful information about a red wine's colour properties and quality.

\section{The effect of red wine maceration temperature Effects on wine colour}

The maceration of crushed grapes is a process known to enhance the colour and aroma of red wine. Skin contact has been shown to improve red wine quality due to the extraction of various phenolic and volatile compounds.

Previously, a number of important studies showed that higher fermentation temperatures increased phenolic extraction and colour parameters (Ough \& Amerine, 1960; Du Plessis, 1973; Gao et al., 1997; Girard et al., 1997, 2001). The main explanation given by researchers for the greater extraction is that higher temperatures increase the permeability of the grapes' skin cells. As a result, the extraction of anthocyanin and also the solubility of other phenolic compounds are increased (Sacchi et al., 2005; Kennedy, 2008; Lukic et al., 2017). In one study (Salinas et al., 2005), the total polyphenol index, total phenol content (Folin index), colour intensity, $a^{*}, b^{*}$ and chroma values, total anthocyanins and the greatest malvidin-3-glucoside content were all shown to increase in rosé wine macerated under higher temperature conditions.

In the studies done by Girard et al. $(1997,2001)$ on Pinot Noir grapes, the researchers demonstrated that the total phenolic content of wine increased with increasing fermentation temperature. Anthocyanins are known to reach a maximum early in fermentation, and then to decrease rapidly, and this was substantiated by Girard et al. (1997), who reported that, while anthocyanins decreased, polymeric pigments increased significantly when the fermentation temperature was raised from $20^{\circ} \mathrm{C}$ to $30^{\circ} \mathrm{C}$. The increase in polymeric pigments with increasing fermentation temperature was also reported by Harbertson et al. (2002),

TABLE 1

Phenolic compounds in red wine (Singleton \& Noble, 1976)

\begin{tabular}{lc}
\hline Phenolic compounds & Concentration $(\mathrm{mg} / \mathrm{L}$ gallic acid equivalent $)$ \\
\hline Non-flavonoids & 200 \\
Flavonoids & \\
Anthocyanins & 150 \\
Condensed tannins & 750 \\
Other flavonoids & 250 \\
Flavonols & 50 \\
\hline
\end{tabular}

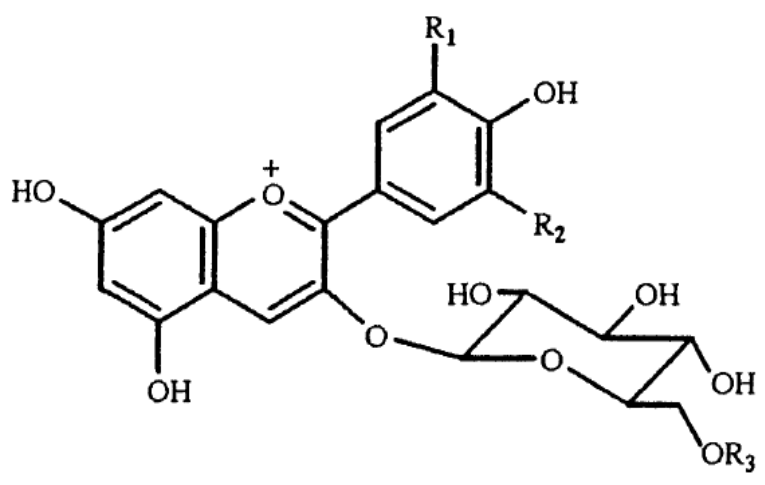

FIGURE 2

The structure of acetylated anthocyanin. $\mathrm{R}_{3}$ represents -acetyl, -p-coumaroyl or -caffeoyl (Monagas et al., 2005). 
TABLE 2

Anthocyanidin compounds in red wine (Monagas et al., 2005)

\begin{tabular}{lll}
\hline Anthocyanidin groups & $\mathrm{R}_{1}$ & $\mathrm{R}_{2}$ \\
\hline Pelargonidin & $\mathrm{H}$ & $\mathrm{H}$ \\
Cyanidin & $\mathrm{OH}$ & $\mathrm{H}$ \\
Delphinidin & $\mathrm{OH}$ & $\mathrm{OH}$ \\
Peonidin & $\mathrm{OCH}_{3}$ & $\mathrm{H}$ \\
Petunidin & $\mathrm{OCH}_{3}$ & $\mathrm{OH}$ \\
Malvidin & $\mathrm{OCH}_{3}$ & $\mathrm{OCH}_{3}$ \\
\hline
\end{tabular}

who noted that, unless adequate tannin is present early in the fermentation to react with anthocyanins, there will be less polymeric pigment in the wine.

Various researchers have demonstrated that fermentations conducted at lower temperatures result in beneficial effects that include increased levels of total phenolic content, anthocyanin, colour intensity and quality in red wines (Girard et al., 2001; Salinas et al., 2005; Şener \& Yildirim, 2013). In these studies, grapes from Vitis vinifera L. Cabernet Franc, Cabernet Sauvignon, Merlot, Pinot Noir and Monastrell were used and fermentation/maceration temperature ranged from $5^{\circ} \mathrm{C}$ to $30^{\circ} \mathrm{C}$. Reynolds et al. (2001) also reported that the lowest proportion of yellow colour was determined in Semillon wines fermented at $15^{\circ} \mathrm{C}$. Increasing the fermentation temperature gradually from $15^{\circ} \mathrm{C}$ to $30^{\circ} \mathrm{C}$ in this study resulted in less of an increase in absorbance at $420 \mathrm{~nm}$. Cejudo-Bastante et al. (2014) found that the phenolic content was significantly higher in cold-macerated wines $\left(5^{\circ} \mathrm{C}\right.$ to $\left.11^{\circ} \mathrm{C}\right)$, even more so when a longer contact time was used. Wines that had been cold macerated for a long time had the highest chroma (colour saturation), and lowest lightness and hue compared with traditional wines at $20^{\circ} \mathrm{C}$

Following on successes in lower temperature fermentations, winemakers are also increasingly using lowtemperature prefermentative techniques (cold-soaking and must-freezing) to improve red wine colour and aroma. The cold-soaking technique has been used for the development of white and rosé wine aroma for many years, but has only gained importance in red wine production in recent years. In these techniques, crushed grapes are held at low temperatures $\left(5^{\circ} \mathrm{C}\right.$ to $\left.10^{\circ} \mathrm{C}\right)$ for several days (2 to 7$)$, and the beginning of the fermentation process is delayed. In cold soaking, the grapes are held at temperatures above zero, while in must freezing, grapes are kept at negative temperatures (Parenti et al., 2004; Gil-Munoz et al., 2009). The extraction of phenols therefore takes place in the absence of ethanol (Gomez-Plaza et al., 2001; Alvarez et al., 2006; Koyama et al., 2007; Heredia et al., 2010; Lukic et al., 2017). These techniques can be used as an alternative method, versus traditional methods, to increase red wine pigments, tannins and aroma. At these low temperatures, the inhibition of enzymatic activities (e.g. polyphenol oxidase) and a delay in microbial growth (e.g. acetic acid bacteria) are achieved, and the oxidation of anthocyanin pigments and aroma compounds is delayed or prevented (Gil-Munoz et al., 2009; Gordillo et al., 2010).

In a study conducted by Busse-Valverde et al. (2010), three treatments, viz. cold-soaking, must-freezing with dry ice (cryomaceration) and the using of maceration enzymes, were performed on Monastrell, Shiraz and Cabernet Sauvignon grapes. According to the results, the proanthocyanidin levels were increased by using cold-soaking $\left(10^{\circ} \mathrm{C}\right.$ and 10 days $)$ in Monastrell and Cabernet Sauvignon wines, whereas this treatment had no significant effect on Shiraz wines. The same results were reported for Monastrell wines, viz. that the highest anthocyanin and proanthocyanin levels were obtained in wines produced with the dry ice method, macerated at $10^{\circ} \mathrm{C}$ and for 10 days. The highest seed-derived proanthocyanidins were determined in cold-soaked wines, whereas the highest levels of skin-derived proanthocyanidins were determined in wines subjected to must-freezing with dry ice. This is in agreement with Busse-Valverde et al. (2010), who showed that the extraction of seed-derived proanthocyanidins takes place in the absence of ethanol, and that the extraction of skin-derived high molecular weight proanthocyanidins becomes easier when using dry ice, giving rise to wines with rich colour quality (Busse-Valverde et al., 2012a). Baiano et al. (2016) also reported that the highest amounts of proanthocyanidins, total anthocyanins, monomeric anthocyanins and total flavonoids were obtained in Nero di Troia wine cold soaked at $5^{\circ} \mathrm{C}$ for 24 hours. Similar results for Negroamaro red wines were reported by Coletta et al. (2013), who stated that the cryomaceration $\left(24 \mathrm{~h}\right.$ at $0^{\circ} \mathrm{C}$ using dry ice) led to enrichment in anthocyanins and to low levels of total polyphenols, whereas ultrasound treatment improved the extraction of all phenol classes compared with control wines macerated for seven days at $25^{\circ} \mathrm{C}$. Gonzalez-Neves et al. (2016) verified that cold-soaking (for five days at $10^{\circ} \mathrm{C}$ to $15^{\circ} \mathrm{C}$ ) increased the anthocyanin contents in Tannat and Merlot red wines, compared with traditional fermentation $\left(23^{\circ} \mathrm{C}\right.$ to $\left.29^{\circ} \mathrm{C}\right)$ and commercial enzyme treatment. In a study conducted by Lukic et al. (2017), lower total anthocyanins and free anthocyanins, and a higher colour intensity were determined in Teran red wine cold macerated at $5^{\circ} \mathrm{C}$ for five days, compared with the control wine (macerated at $23^{\circ} \mathrm{C}$ ). The higher levels of total and free anthocyanins, and of hue values, were obtained in the control wine in this case. 


\section{Effects on sensory properties}

Besides the colorimetric properties, many compounds that are responsible for the sensory characteristics of the wine are extracted during maceration. These compounds are related to the gustatory sensations of the wine, such as bitterness, astringency and body, and olfactory sense such as aroma. The astringency and bitterness of young red wines are related to the concentrations of various phenolic acids and flavonols. Bitterness comes from the seed-derived monomeric flavonols (e.g. catechins), and astringency is from the skin-derived polymeric flavonols (e.g. tannins). By increasing the molecular weight of the flavonol compounds, the astringency characteristic increases, whereas bitterness decreases. The very high astringency of tannins is explained by their increased ability to form complexes with peptides and proteins. Tannins interact with salivary proteins, and the subsequent aggregation and precipitation of protein-tannin complexes results in the gustatory sense of astringency (Clifford, 1986; Guinard et al., 1986; Sarni-Manchado et al., 1999; Adams, 2006; Cheynier et al., 2006; Kennedy et al., 2006).

It is well known that wine aroma and flavour characteristics are related to grape variety composition and also oenological processes. Various researchers have demonstrated that fermentations kept at low temperatures or underwent a prefermentative cold-soaking result in higher organoleptic properties and rich aroma in white, rosé and red wines (Long \& Lindblom, 1987; Miller et al., 1987, Girard et al., 2001; Salinas et al., 2003; Peinado et al., 2004; Şener \& Yildirim, 2013). On the other hand, it has also been reported that maceration temperature has an insignificant effect on wine sensory properties (Mahon et al., 1999; Casassa et al., 2015; Baiano et al., 2016).

Numerous researchers have related the higher sensory scores given to cold-fermented wines to decreased oxidation of aromatic compounds. Some of these studies have also reported that the highest intensity of 'fruity' or 'flowery' aroma was obtained in cold-fermented wines (Girard et al., 2001; Reynolds et al., 2001; Salinas et al., 2003; Peinado et al., 2004). Similarly, a study conducted by Girard et al. (2001) reported that the best 'tropical fruity' and 'spicy' characteristics were obtained in Pinor Noir red wine fermented at $15^{\circ} \mathrm{C}$, compared to $20^{\circ} \mathrm{C}$ and $30^{\circ} \mathrm{C}$. The highest scores for fruity characteristics, such as 'cassis', 'clove', 'fresh fruity' and rosé aroma, were also evaluated in Cabernet Sauvignon red wine cold-macerated $\left(15^{\circ} \mathrm{C}\right)$ for six days versus macerated at $25^{\circ} \mathrm{C}$ for three to six days (Şener $\&$ Yildirim, 2013).

It is likely that floral aroma resulted from the retention, at low temperatures, of terpene and ester compounds. Salinas et al. (2003) reported that the highest ester and terpene levels were obtained in Monastrell rosé wine macerated at $15^{\circ} \mathrm{C}$, compared with traditional winemaking conditions. The effect of prefermentative maceration temperatures $(5,10$ and $15^{\circ} \mathrm{C}$ ) on the volatile composition of Monastrell rosé wine showed that the highest sensory scores were evaluated in wine samples macerated at $15^{\circ} \mathrm{C}$ (Salinas et al., 2005). Similar results for Monastrell rosé wine were also reported in a previous study, in which the highest ester levels were obtained in wine macerated at $10^{\circ} \mathrm{C}$ (Gil-Munoz et al., 1999).
In the study conducted for the must-freezing method, Tuscan Sangiovese grapes were held at low temperatures (from $-5^{\circ} \mathrm{C}$ to $5^{\circ} \mathrm{C}$ ) for 48 hours by using dry ice and liquid nitrogen. The wines were characterised through the use of chemical analyses and sensory evaluation and showed higher quality overall, which may have resulted from the higher extraction of polyphenolic compounds at lower cold-maceration temperatures. It has also been reported that liquid nitrogen is more effective than dry ice at the same temperature (Parenti et al., 2004).

\section{The effect of duration of red wine maceration Effects on wine colour}

The duration of maceration (the time that crushed grapes are in contact with the juice or wine) is of vital importance for the extraction of phenolic compounds into the must. Prolonged maceration time has been shown to cause an increase in colour intensity and some colour parameters (Yokotsuka et al., 2000; Gomez-Plaza et al., 2001). Many researchers have reported that the highest colour parameters and anthocyanin levels are obtained in wine macerated for between three and six days (Ribereau-Gayon \& Glories, 1987; Sims \& Bates, 1994; Reynolds et al., 2001; Kelebek et al., 2006; Şener \& Yildirim, 2013), noting that colour intensity values start to decrease during prolonged maceration times. This can be explained by the absorption of the anthocyanins by grapes seeds, stems, skins, tannins and wine yeast during winemaking. This critical maceration time differs depending on grape variety, ripeness level and other winemaking conditions (Peynaud, 1981; Sims \& Bates, 1994).

Due to their interactions with anthocyanins, tannins are the important compounds in the colour development and stability of red wine. Depending on the duration of pomace contact with the seeds and skins, the amount of tannins increases continuously during prolonged exposure (Oszmianski et al., 1986; Kelebek et al., 2006), whereas similar trends are not obtained in anthocyanins with long prolonged maceration times. Although anthocyanin levels were found to increase gradually during the initial maceration (two to three days) and later decrease during subsequent contact (four to five days), polymeric pigments increased due to the increasing in tannin concentrations during prolonged maceration (Sacchi et al., 2005). Reynolds et al. (2001) also reported that the highest total pigments and polymeric pigments related to tannin extraction were determined in Shiraz wines macerated for three days.

Gomez-Plaza et al. (2001) demonstrated that longer pomace contact during fermentation (10 days versus four or five days) increased the concentration of anthocyanins and tannins in the wines at bottling, and their polymeric pigment content after one year in the bottle. Another study comparing the maceration of Cabernet Sauvignon wine for seven, 13 and 21 days showed that total phenols, gallic acid and flavanols all increased with skin contact time (Auw et al., 1996), and a similar result was reported for Cabernet Sauvignon wine by Kudo and Sodeyama (2002). Kocabey et al. (2016) showed that the highest total phenolic content, individual phenolic contents, colour intensity, tint value and antioxidant activity were obtained in Vitis vinifera L. Karaoglan red wines macerated for 15 days, versus five and 10 days, with the total 
anthocyanin levels highest in wines macerated for five days. Colour intensity and tint values also were increased with extended duration of maceration. All these studies support the expectation that prolonged maceration causes an increase in tannins, which may cause an increase in polymeric pigment formation, but not in anthocyanins.

\section{Effects on sensory properties}

As discussed before, skin maceration is an essential winemaking technique that affects the sensory properties and aroma of red wine. Many studies have shown that wines with desirable astringency, aroma and body character can be produced by controlling maceration conditions (such as time and temperature). In addition, some aroma and flavour compounds, such as tannins, terpenes, esters etc., may also interact with each other during the maceration process (Cheynier et al., 2006).

According to Suriano et al. (2015), the maceration time (three, six and eight hours) had a significant effect on the aroma, flavour and colour characteristics of Bombino Nero (Vitis vinifera L.) rosé wine. Although a longer maceration time was positively correlated with the colour stability of wine over time, a prolonged maceration was not necessary to enrich the pleasant 'fruity and flowery' aroma. The wines macerated for six hours had the highest 'berries', 'cherry', 'exotic fruity', 'fresh herbaceous' and 'flowery' aroma, acidity, body and overall judgement scores, therefore this wine was evaluated as more fragrant and delicate.

Yilmaztekin et al. (2015) reported that a maximum free aroma content was achieved in Karaoglan red wines after five days of maceration, and that this showed a decrease at 10 days and then increased again at 15 days. The free aroma compounds identified in the final wine were characterised by large amounts of higher alcohols, monoterpenic alcohols, esters and varietal aroma. On the other hand, the concentration of glycosidically bound aroma compounds also increased during maceration. There were no significant differences in the sensory quality attributes linked to appearance and clarity, but significant differences were noted for colour, aroma, bouquet, taste, body, bitterness and overall, and for total scores $(P<0.05)$. The best panel scores were found by the assessors to be in wines macerated for 10 days.

In a study comparing the maceration of Monastrell, Shiraz and Cabernet Sauvignon red wines for five, 10 and 20 days, astringency increased with increasing maceration time, whereas no significant differences were found for bitterness, except in Cabernet Sauvignon wines (BusseValverde et al., 2012b). This could be explained by the higher concentration of proanthocyanidins in these wines. Although Shiraz grapes had the lowest levels of seed- and skin-derived proanthocyanidins, Shiraz wines macerated at 20 days had the highest levels of proanthocyanidins in the latter study compared to the other varieties. All these results explain the importance of maceration time on wine sensory properties, which include the perception of astringency, bitterness, aroma and body.

\section{CONCLUSIONS}

The duration and temperature of maceration have significant effects on wine quality, and higher (traditional red wine) fermentation temperatures have been reported in many research studies to increase the extraction of phenolic compounds and to enhance the colour parameters. However, from this review of the literature it is clear that the maceration (before or during fermentation) of grapes and juice or wine at low temperature ranges $\left(10^{\circ} \mathrm{C}\right.$ to $\left.15^{\circ} \mathrm{C}\right)$ resulted in the highest levels of total phenolic content, total anthocyanins, polymeric pigments, colour intensity and appearance in the resultant red wines. At these lower temperatures, the beginning of fermentation is delayed, therefore the extraction of phenolic compounds takes place in the absence of ethanol, and the oxidation of aroma compounds is delayed or prevented. Furthermore, inhibition of some enzymatic activities and undesirable microbial growth can be achieved. A shorter contact time or a maceration duration of around three to six days also seems to be optimum for increased anthocyanin levels, colour intensity and some colour parameters. Although prolonged maceration time can increase tannins, which may cause increases in polymeric pigment formation and astringency, it does not cause an increase in anthocyanins. Wines with richer 'fruity', 'flowery' and 'spicy' aromas can be produced at low maceration temperatures (around $15^{\circ} \mathrm{C}$ ) because of the lower levels of oxidation of aromatic compounds. As a result, red wines with desirable colour, astringency, aroma, flavour and body characteristics can be produced by controlling both the temperature and duration of maceration. Further studies would be useful for a more comprehensive assessment of the effects of cold maceration on red wine, especially with regard to the effects on bitterness, astringency and ageing potential.

\section{LITERATURE CITED}

Adams, D.O., 2006. Phenolics and ripening in grape berries. Am. J. Enol. Vitic. 57, 249-255.

Alvarez, I., Aleixandre, J.L., Garcia, M.J. \& Lizama, V., 2006. Impact of prefermentative maceration on the phenolic and volatile compounds in Monastrell red wines. Anal. Chim. Acta 563, 109-115.

Auw, J.M., Blanco, V., O’Keefe, S.F. \& Sims, C.A., 1996. Effect of processing on the phenolics and color of Cabernet Sauvignon, Chambourcin and Noble wines and juices. Am. J. Enol. Vitic. 47, 279-286.

Baiano, A., Previtali, M.A., Viggiani, I. \& Gianni, A.D., 2016. Maceration procedures alternative to the standard vinification in red: the case of Nero di Troia wine. Eur. Food Res. Tech. 242, 825-835.

Bakker, J., Bridle, P. \& Timberlake, C.F., 1986. Tristimulus measurements (CIELAB 76) of port wine colour. Vitis 25, 67-78.

Boulton, R., 2001. The copigmentation of anthocyanins and its role in the color of red wine: A critical review. Am. J. Enol. Vitic. 52, 67-87.

Busse-Valverde, N., Bautista-Ortin, A.B., Gomez-Plaza, E., FernandezFernandez, J.I. \& Gil-Munoz, R., 2012b. Influence of skin maceration time on the proanthocyanidin content of red wines. Eur. Food Res. Tech. 235, 1117-1123.

Busse-Valvarde, N., Gomez-Plaza, E., Lopez-Roca, J.M., Gil-Munoz, R. \& Baustita-Ortin, B.B., 2012a. The extraction of anthocyanins and proanthocyanidins from grapes to wine during fermentative maceration is affected by the enological technique. J. Agric. Food. Chem. 59, 5450-5455. 
Busse-Valvarde, N., Gomez-Plaza, E., Lopez-Roca, J.M., Gil-Munoz, R., Fernandez-Fernandez, J.I. \& Baustita-Ortin, B.B., 2010. Effect of different enological practices on skin and seed proanthocyanidins in three varietal wines. J. Agric. Food. Chem. 58, 11333-11339.

Casassa, L.F, Bolcata, E.A. \& Sari, S.E., 2015. Chemical, chromatic and sensory attributes of 6 red wines produced with prefermentative cold soak. Food Chem. 174, 110-118.

Cejudo-Bastante, M.J., Gordillo, B., Hernanz. D., Escudero-Gilete, M.L., Gonzalez-Miret, M.L. \& Heredia, FJ., 2014. Effect of the time of cold maceration on the evolution of phenolic compounds and colour of Syrah wines elaborated in warm climate. Int. J. Food Sci. Tech. 49, 1886-1892.

Cheynier, V., Duenas-Paton, M., Salas, E., Maury, C., Souquet, J.M., Sarni-Manchado, P. \& Fulcrand, H., 2006. Structure and properties of wine pigments and tannins. Am. J. Enol. Vitic. 57, 298-305.

CIE, 1986 ( $2^{\text {nd }}$ ed). Colourimetry. Central Bureau of the Commission Internationale de L'Eclairage, Vienna.

Clifford, M.N., 1986. Phenol-protein interactions and their possible significance for astringency. In: Birch, G. \& Lindley, M. (eds). Interaction of food components. Elsevier, London. pp 143 - 163.

Coletta, A., Trani, A., Faccia, M., Punzi, R., Dipalmo, T., Crupi, P., Antonacci, D. \& Gambacorta, D., 2013. Influence of viticultural practices and winemaking technologies on phenolic composition and sensory characteristics of Negroamaro red wines. Int. J. Food Sci. Tech. 48, 2215 2227 .

Du Plessis, C.S., 1973. Browning of white wines. Wynboer 499, 11-13

Gao, L., Girard, B., Mazza, G. \& Reynolds, A.G., 1997. Changes in anthocyanins and color characteristics of Pinot Noir wines during different vinification processes. J. Agric. Food Chem. 45, 2003-2008.

Gil-Munoz, R., Gomez-Plaza, E., Martinez, A. \& Lopez-Roca, J.M., 1999 Evolution of the phenolic compounds during wine fermentation and postfermentation: Influence of grape temperature. J. Food Compos. Anal. 12, 259-272.

Gil-Munoz, R., Moreno-Perez, A., Vila-Lopez, R., Fernandez-Fernandez, J.I., Martinez-Cutillas, A. \& Gomez-Plaza, E., 2009. Influence of low temperature prefermentative techniques on chromatic and phenolic characteristics of Syrah and Cabernet Sauvignon wines. Eur. Food Res. Technol. 228, 777-788.

Girard, B., Kopp, T.G., Reynold, A.G. \& Cliff, M., 1997. Influence of vinification treatments on aroma constituents and sensory descriptors of Pinot Noir wines. Am. J. Enol. Vitic. 48, 198-206.

Girard, B., Yuksel, D., Cliff, M.A., Delaquis, P. \& Reynolds, A.G., 2001. Vinification effects on the sensory, color and GC profiles of Pinot Noir wines from British Colombia. Food Res. Int. 34, 483-499.

Glories, Y., 1984. La couleur des vins rouges. Cannaissance Vigne Vin 18, 253-271.

Glories Y., 1999. Substances responsible for astringency, bitterness and wine colour. J. Int. Sci. Vigne Vin, 33, 107-110.

Gomez-Plaza, E., Gil-Munoz, R., Lopez-Roca, J.M., Martinez-Cuttilas, A. \& Fernandez-Fernandez, J.I., 2001. Phenolic compounds and colour stability of red wines: Effect of skin maceration time. Am. J. Enol. Vitic. 52, 271-275.

Gomez-Plaza, E., Gil-Munoz, R., Lopez-Roca, J.M., Martinez-Cuttilas, A. \& Fernandez-Fernandez, J.I., 2002. Maintenance of color composition of a red wine during storage: Influence of prefermentative practices maceration time and storage. Lebensm.-Wiss. Technol. 35, 46-53.

Gonzalez-Neves, G., Favre, G., Piccardo, D. \& Graciela, G., 2016 Anthocyanin profile of young red wines of Tannat, Syrah and Merlot made using maceration enzymes and cold soak. Int. J. Food Sci. Tech. 51, 260 267.
Gordillo, B., Lopez-Infante, M.I., Ramirez-Perez, P., Gonzalez-Miret, M.L. \& Heredia, F.J., 2010. Influence of prefermentative cold maceration on the color and anthocyanin copigmentation of organic Tempranillo wines elaborated in a warm climate. J. Agric. Food Chem. 58, 6797-6803.

Guinard, J.X., Pangborn, R.M. \& Lewis, R.M., 1986. Preliminary studies on acidity-astringency interactions in model solutions and wines. J. Sci. Food Agric. 37, 811-817.

Gutierrez, I.H., Lorenzo, E.S.P. \& Espinosa, A.V., 2005. Phenolic composition and magnitude of copigmentation in young and shortly aged red wines made from the cultivars, Cabernet Sauvignon, Cencibel and Syrah. Food Chem. 92, 269-283.

Harbertson, J.F., King, A., Block, D.E. \& Adams, D.O., 2002. Factors that influence tannin extraction and formation of polymeric pigments during winemaking. Am. J. Enol. Vitic. 53, 245A

Harbertson, J.F. \& Spayd, S., 2006. Measuring phenolics in the winery. Am. J. Enol. Vitic. 57(3), 280-288.

Heredia, F.J., Escudero-Gilete, M.L., Hernanz, D., Gordillo, B., MelendezMartines, A.J., Vicario, I.M. \& Gonzalez-Miret ML, 2010. Influence of the refrigeration technique on the colour and phenolic composition of Syrah red wines obtained by pre-fermentative cold maceration. Food Chem. 118 $377-383$

Jackson, D.I. \& Lombard, P.B., 1993. Environmental and management practices affecting grape composition and wine quality - A review. Am. J. Enol. Vitic. 44, 409-430.

Kallithraka, S., Bakker, J. \& Clifford, M.N., 1997. Evaluation of bitterness and astringency of (+)-catechin and (-)-epicatechin in red wine and in model solution. J. Sens. Stud. 12, 25-37.

Kanellis, A.K. \& Roubelakis-Angelakis, K.A., 1993. Grape. In: Seymour, G.B., Taylor, J.E. \& Tucker, G.A. (eds). Biochemistry of fruit ripening. Chapman and Hall, London. pp, 189 - 234.

Kelebek, H., Canbas, A., Selli, S., Saucier, C., Jourdes, M. \& Glories, Y., 2006. Influence of different maceration times on the anthocyanin composition of wines made from Vitis vinifera L. cvs. Bogazkere and Okuzgozu. J. Food Eng. 77, 1012-1017.

Kennedy, J.A., 2008. Grape and wine phenolics: Observations and recent findings. Cien. Inv. Agr. 35(2) 107-120.

Kennedy, J.A., Saucier, C. \& Glories, Y., 2006. Grape and wine phenolics: History and perspective. Am. J. Enol. Vitic. 57(3), 239-247.

Kocabey, N., Yilmaztekin, M. \& Hayaloglu, A.A., 2016. Effect of maceration duration on physicochemical characteristics, organic acid, phenolic compounds and antioxidant activity of red wines from Vitis vinifera L. Karaoglan. J. Food Sci. Tech. 53(9), 3557-3565.

Koyama, K., Goto-Yamamoto, N. \& Hashizume, K., 2007. Influence of maceration temperature in red wine vinification on extraction of phenolics from berry skins and seeds of grape (Vitis vinifera). Biosci. Biotech. Biochem. 71, 958-965.

Kudo, M. \& Sodeyama, M., 2002. Weight distribution of red wine polyphenols affected by length of maceration. Am. J. Enol. Vitic. 53, 332A

Long, Z.R. \& Lindblom, B., 1987. Juice oxidation in California Chardonnay In Proc. $6^{\text {th }}$ Aust. Wine Ind. Tech. Conf., Adelaide, Australia. pp. $267-271$

Lukic, I., Budic-Leto, I., Bubola, M., Damijanic, K. \& Staver, M., 2017. Pre-fermentative cold maceration, saignée, and various thermal treatments as options for modulating volatile aroma and phenol profiles of red wine. Food Chem. 224, 251-261.

Mahon, H.M., Zoecklein, B.W. \& Jasinski, Y.W., 1999. The effects of prefermentation maceration temperature and percent alcohol $(\mathrm{v} / \mathrm{v})$ at press on the concentration of Cabernet Sauvignon grape glycosides and glycoside fractions. Am. J. Enol. Vitic. 50, 385-390. 
Mazza G., 1995. Anthocyanins in grape and grape products. Crit. Rev. Food Sci. Nutr. 35, 341-371

Mazza, G. \& Miniati, E., 1993. Grapes. In: Mazza, G. \& Miniati, E. (eds). Anthocyanins in fruits, vegetables and grains. CRC Press, Boca Raton, USA. pp. 149 - 199.

Miller, G., Amon, J. \& Simpson, R., 1987. Loss of aroma compounds in carbon dioxide effluent during white wine fermentation. Food Technol. Aust. 39, 246-249

Monagas, M., Bartolome, B. \& Gomez-Cordoves, C., 2005. Updated knowledge about the presence of phenolic compounds in wine. Crit. Rev. Food. Sci. 45(2), 85-118

Oszmianski, J., Romeyer, F.M., Sapis, J.C. \& Macheix, J.J., 1986. Grape seed phenolics: Extraction as affected by some conditions occurring during wine processing. Am. J. Enol. Vitic. 37, 7-121.

Ough, C.S. \& Amerine, M.A., 1960. Studies on controlled fermentation. V. Effects on color, composition, and quality of red wines. Am. J. Enol. Vitic. 12, 9-19.

Palomo, E.S., Hidalgo, M.C.D., Gonzales-Vinas, M.A. \& Perez-Coello, M.S., 2005. Aroma enhancement in wines from different grape varieties using exogenous glycosidases. Food Chem. 92, 627-635.

Parenti, A., Spugnoli, P., Calamai, L., Ferrari, S. \& Gor, C., 2004. Effects of cold maceration on red wine quality from Tuscan Sangiovese grape. Eur. Food Res. Technol. 218, 360-366.

Peinado, R.A., Moreno, J., Bueno, J.E., Moreno, J.A. \& Mauricio, J.C., 2004. Comparative study of aromatic compounds in two young white wines subjected top pre-fermentative cryomaceration. Food Chem. 84, 858-590.

Peynaud, E., 1981. Knowing and making wine. John Wiley \& Sons, Hoboken, NJ.

Pogorzelski, E. \& Wilkowska, A., 2007. Flavour enhancement through the enzymatic hydrolysis of glycosidic aroma precursors in juices and wine beverages: a review. Flavour Frag. J. 22, 251-254.

Price, S.F. \& Vallado, M., 1995. Effect of fermentation practices on anthocyanin and phenol composition of Pinot Noir wines. Am. J. Enol. Vitic. 46, 404. Abstract. 46 ${ }^{\text {th }}$ Annual Meeting Am. Soc. Enol. Vitic., June 1995, Portland, Oregon.

Rapp A., 1988. Aroma substances from gas chromatographic analysis. In Linskens, H.F. \& Jackson, J.F. (eds). Wine analysis. Springer-Verlag, Berlin. pp. $29-66$.

Reynolds, A., Cliff, M., Girard, B. \& Kopp, T.G., 2001. Influence of fermentation temperature on composition and sensory properties of Semillon and Shiraz wines. Am. J. Enol. Vitic. 52, 235-240.
Ribereau-Gayon, P. \& Glories, Y., 1987. Phenolics in grapes and wine. In Proc. $6^{\text {th }}$ Aust. Wine Ind. Tech. Conf., July, Adelaide, Australia. pp. $247-$ 256

Sacchi, K.L., Bisson, L.F. \& Adams, D.O., 2005. A review of the effect of winemaking techniques on phenolic extraction in red wines. Am. J. Enol. Vitic. 56(3), 197-206.

Salinas, M.R., Garijo, J., Pardo, F., Zalacain, A. \& Alonso, G.L., 2003. Color, polyphenol and aroma compounds in rosé wines after prefermentative maceration and enzymatic treatments. Am. J. Enol. Vitic. 54(3), 195-202.

Salinas, M.R., Garijo, J., Pardo, F., Zalacain, A. \& Alonso, G.L., 2005. Influence of prefermentative maceration temperatures on the color and the phenolic and volatile composition of rosé wines. J. Sci. Food Agr. 85, 1527 1536.

Sarni-Manchado, P., Cheynier, V. \& Moutounet, M., 1999. Interactions of grape seed tannins with salivary proteins. J. Agric. Food Chem. 47, 42-47.

Şener, H. \& Yildirim, H.K. 2013. Influence of different maceration time and temperatures on total phenols, colour and sensory properties of Cabernet Sauvignon wines. Food Sci. Technol. Int. 19(6), 523-533.

Sims, C.A. \& Bates, R.P., 1994. Effect of skin fermentation time on the phenols, anthocyanins, ellagic acid sediment and sensory characteristics of a red Vitis rotundifolia wine. Am. J. Enol. Vitic. 45, 56-62.

Singleton, V.L. \& Noble, A.C., 1976. Wine flavor and phenolic substances. In: Charalambous, G. \& Katz, I. (eds). Phenolic, sulfur and nitrogen compounds in food flavors. American Chemical Society, Washington DC. pp. $47-70$.

Singleton, V.L. \& Rossi, J.A., 1965. Colourimetry of total phenolics with phosphomolybdic and phosphotungstic acid reagents. Am. J. Enol. Vitic. $16,144-158$

Suriano, S., Basile, T., Tarricone, L. Gennaro, D.D. \& Tamborra, P., 2015. Effects of skin maceration time on the phenolic and sensory characteristics of Bombino Nero rosé wines. Ital. J. Agron. 10(1), 21-29.

Vidal, S., Francis, L., Guyot, S., Marnet, N., Kwiatkowski, M., Gawel, R., Cheynier, V. \& Waters, E.J., 2003. The mouth-feel properties of grape and apple proanthocyanidins in a wine-like medium. J. Sci. Food Agric. 83, 564573

Yilmaztekin, M., Kocabey, N. \& Hayaloglu, A.A., 2015. Effect of maceration time on free and bound volatiles of red wines from cv. Karaoglan (Vitis vinifera L.) grapes grown in Arapgir, Turkey. J. Food Sci. 80(3), 556-563.

Yokotsuka, K., Sato, M., Ueno, N. \& Singleton, V.L., 2000. Colour and sensory characteristics of Merlot red wines caused by prolonged pomace contact. J. Wine Res. 11, 7-18. 